\title{
El salterio y breviario laico en neerlandés medieval: ¿libros escritos por hombres para dominar la devoción femenina? (*)
}

'[...] He aquí que miré y vi una enorme multitud cuyo número nadie podía contar [...] (Apoc. 7, 9). Esta cita del libro del Apocalipsis abre la introducción de Boeken voor de eeuwigheid (Libros para la eternidad), (1) una colección de artículos que han llegado a ser muy importantes para la investigación de la literatura religiosa en neerlandés medieval (2). En verdad, existen miles de manuscritos religiosos en prosa, compuestos en neerlandés medieval y, hasta 1993, solo una pequeña parte de ellos era conocida por los estudiosos. Además de la introducción, Boeken voor de eeuwigheid contiene varios artículos sobre diferentes textos y géneros religiosos, todos ellos escritos en neerlandés medieval, como por ejemplo, traducciones del Nuevo Testamento y Libros de Horas (horae). Los artículos no cubren todos los textos ni siquiera todos los géneros existentes, pero han logrado que un mayor número de estudiosos se interesen en ese campo de la literatura neerlandesa medieval. Uno de los géneros que no fue mencionado en Boeken voor de eeuwigheid -y que nunca había sido previamente estudiado- fue el de las traducciones neerlandesas de himnos latinos (Canciones para los Oficios Divinos) y de secuencias latinas para la Misa. Por esta razón inicié en 1999 una investigación doctoral en la Universidad de Gante (Bélgica), con el propósito de conocer la naturaleza, distribución y función de estas traducciones de himnos y de secuencias, así como sus fuentes (3). El estudio que presento aquí es un resumen de los principales resultados de este proyecto.

En los primeros años de la investigación quedó claro que algunas de las traducciones neerlandesas de himnos y secuencias latinas se podían encontrar en algunos

(*) El texto original de este artículo fue una conferencia dictada en la Universidad de Chile el día 2 de noviembre de 2004 en el marco del Proyecto Bilateral Chile/Flandes Hablándole al ojo. Texto, imagen y género en la Edad Media y la temprana Modernidad (Universidad de Chile-Universidad de Ghent, 2004-2006). Quiero agradecer a la señorita Natalia Sáez y a la Prof. M. E. Góngora (Universidad de Chile) por la traducción de este texto desde el inglés

(1) Th. Mertens, 'Boeken voor de eeuwigheid. Ter inleiding', in: MERTENS 1993, p. 8-35 en 361-372.

(2) MERTENS 1993.

(3) Este proyecto de investigación (guiado por el Prof. Dr. J. Reynaert, del departamento de Literatura neerlandesa, Universidad de Gante, University of Ghent) culminó en mi tesis doctoral (DESPLENTER 2004b). 
de los salterios traducidos y de los así llamado 'breviarios [para] laicos', libros escritos en neerlandés medieval y que siguen el modelo de los salterios latinos y de los breviarios latinos compuestos para seguir los Oficios. Y gracias a algunas de estas fuentes escritas en neerlandés medieval, se puede confirmar que ellas fueron usadas o poseídas por mujeres que llevaban una vida religiosa (4).

Nunca se ha hecho mucha investigación sobre las traducciones de salterios en neerlandés medieval. Esto resulta sin duda sorprendente, puesto que estos textos pueden ser aún encontrados en más de ochenta manuscritos. En un pequeño artículo de hace más de 65 años, un académico neerlandés dividió las traducciones en tres diferentes tradiciones de textos (5). Las primeras dos se originaron en el sur de los Países Bajos (el actual Flandes), y fueron realizadas durante el siglo catorce, mientras que la traducción más reciente fue hecha en la región norte (la actual Holanda). Anteriormente a mi investigación del doctorado, la fecha exacta en la cual esta última traducción fue hecha era incierta; desarrollé sin embargo una hipótesis en la cual argumenté que esta fecha debía ser entre 1410 y 1420, o más bien dentro del primer cuarto del siglo quince (6). Esta tercera tradición fue además la más influyente: la mayoría los salterios en neerlandés medieval que aún quedan pertenecen a esta tradición.

En este trabajo dejaremos de lado las primeras dos traducciones de los salterios y nos enfocaremos en la tercera. Siempre ha estado claro que la tercera traducción del salterio fue llevada a cabo en el ámbito del movimiento religioso conocido como la Devotio Moderna (7). Básicamente, este movimiento extremadamente influyente se inició en el año 1374, cuando Geert Grote (Gerardus Magnus) de Deventer -un pueblo en la región noreste de los Países Bajos- cedió su morada a un pequeño grupo de mujeres quienes querían llevar una vida religiosa (8). Más tarde ellas se transformarían en las llamadas Hermanas de la Vida Común. Hacia 1383, Geert Grote -quien vivía en el mismo hogar que estas mujeres, pero en una habitación separada- compuso y parcialmente tradujo un Libro de Horas al neerlandés (9). Es

(4) Estas observaciones preliminares fueron escritas en DESPLENTER 2004a.

(5) C.C. De Bruin, 'Bijdrage tot de Geschiedenis der Middelnederlandse Psalmvertalingen', in: Bundel opstellen van oud-leerlingen, aangeboden aan Prof. Dr. C.G. De Vooys, ter gelegenheid van zijn vijfentwintigjarig hoogleraarschap aan de Rijksuniversiteit te Utrecht, 1915 - 16 october 1940, Groningen/Batavia 1940, p. 46-74.

(6) DESPLENTER 2004b, p. 210-211.

(7) La literatura secundaria sobre la Devotio Moderna es abundante, si bien el estudio clásico en inglés sigue siendo el de Post (1968). Una revisión reciente, con un énfasis en las comunidades femeninas que pertenecieron al movimiento, se presenta en SCHEEPSMA 2004, p. 1-30.

(8) Existen biografías de Geert Grote como la de G. Epiney-Burgard, Gérard Grote (1340-1384) et les débuts de la Dévotion moderne, Wiesbaden 1970 (Veröffentlichungen des Instituts für europäische Geschichte Mainz, Abteilung abendländische Religionsgeschichte 54) y A.G. Weiler, 'Leven en werken van Geert Grote 1340-1384', in: C.C. De Bruin, E. Persoons, A.G. Weiler, Geert Grote en de Moderne Devotie, Zutphen 1984, p. 9-55.

(9) La edición más reciente de este Libro de Horas es la de N. van Wijk (ed.), Het getijdenboek van Geert Grote, naar het Haagse handschrift 133 E 21 uitgegeven, Leiden 1940. Una revisión reciente de estudios ya antiguos y un estado de la cuestión lo presentan R. van Dijk: 'Het getijdenboek van Geert Grote', in: E. Cockx-Indestege, J. Deschamps, F. Hendrickx (ed.), Spiritualia Neerlandica. Opstellen voor dr. Albert Ampe, Antwerpen 1990, p. 456-494 [también en Ons Geestelijk Erf 64 (1990), p. 156-194] y asimismo R.Th.M. van Dijk, 'Methodologische kanttekeningen bij het onderzoek van getijdenboeken’, in MERTENS 1993, p. 210-229 en 434-436. 
evidente que él escribió este libro para las mujeres que vivían en su casa. Todas estas mujeres eran pobres y habían vivido solas. Además, es posible confirmar que ellas poseían poca educación y que no entendían latín, el idioma oficial de la liturgia medieval. Al traducir y componer algunas horae en neerlandés, Geert Grote satisfizo una necesidad de textos religiosos. Como en todo Libro de Horas, estas horae no eran traducciones de los verdaderos oficios religiosos, pero sí contenían algunos textos litúrgicos traducidos, por ejemplo sesenta salmos. Durante el siglo quince, este Libro de Horas de Geert Grote llegó a ser el texto más divulgado en neerlandés medieval -según una estimación, existen aún entre 800 y 2.000 copias- y fue leído por religiosas y religiosos no solamente en la totalidad de los Países Bajos, sino que también en vastas regiones de Alemania del norte.

Como ya mencioné, el Libro de Horas de Geert Grote contiene la traducción de una parte del salterio, alrededor de sesenta salmos. Los mismos textos son parte de la tercera traducción completa del salterio al neerlandés medieval ya mencionada y que es conocida como 'El salterio de la Devotio Moderna' (10). Obviamente la primera pregunta apunta a saber cuál libro fue el primero, si el libro de Horas o bien el salterio. Aunque esta pregunta y otras más no han sido aún completamente respondidas, parece muy probable que el salterio completo fue terminado después que el Libro de Horas (11). Alguien debió haber tomado las traducciones de los salmos de Geert Grote y debió haber traducido el resto de los salmos de la misma manera. Sin embargo, no está claro quién fue el responsable de esta labor: la mayoría de los académicos pensaron en Johannes Scutken (†1423), el bibliotecario de la colección de manuscritos neerlandeses en el monasterio de Canónigos Regulares de Windesheim. Windesheim se transformó en el principal hogar de una de las más grandes asociaciones religiosas en los Países Bajos, el Capítulo de Windesheim, y tuvo una importancia crucial en el inmenso éxito que experimentó el movimiento de la Devotio Moderna. Una crónica escrita en la segunda mitad del siglo quince, la Chronicon Windeshemense, menciona que el bibliotecario Johannes Scutken realizó una traducción del salterio para la gente del monasterio que no entendía latín (12). La crónica no indica que él haya completado la traducción del libro, y por esto algunos académicos aún dudan de su autoría. En los próximos tres años espero aclarar lo que realmente sucedió (13).

Ahora, la pregunta más importante es ¿por qué se tuvo que hacer una traducción del salterio completo en neerlandés medieval? El Libro de Salmos no es un

(10) J.G. Heymans (ed.), Psalteria Devotionis Modernae, Leiden 1978 (Corpus Sacrae Scripturae Neerlandicae Medii Aevi. Series Minor, Tomus V: Psalteria. Volumen II) es una edición del Salterio de la Devotio Moderna.

(11) La más reciente publicación que resume los datos concernientes al Salterio de la Devotio Moderna está en J.A.A.M. Biemans, Codices Manuscripti Sacrae Scripturae Neerlandicae, Leiden 1984 (Corpus Sacrae Scripturae Neerlandicae Medii Aevi. Catalogus), p. 100-110.

(12) K. Grube (ed.), Des Augustinerpropstes Iohannes Busch Chronicon Windeshemense und Liber de reformatione monasteriorum, Halle 1886, p. 192.

(13) Mi nuevo proyecto de investigación (octubre 2004-septiembre 2007), un estudio de Postdoctorado auspiciado por el Fondo de Investigación Científica de Flandes (Bélgica) deberá culminar en un estudio de todas las traducciones de salterios al neerlandés medieval, considerando que estos son textos ejemplares de la literatura devocional y de oración en neerlandés medieval, en su marco religioso, cultural y social. 
libro sencillo: en el tiempo y lugar en que los salmos fueron escritos, los símbolos usados en los textos eran comunes a todos, pero se puede dudar que aquellas personas poco educadas realmente entendieran el contenido del salterio de la Devotio Moderna; si hubiesen sido más educadas, no hubieran necesitado una traducción en su propia lengua vernácula. Por lo demás, ya existía un libro de devoción que podía ser usado por hombres, pero que era usado principalmente por aquellas mujeres que deseaban llevar una vida religiosa, pero que no entendían latín: el Libro de Horas escrito por Geert Grote.

Ciertamente, considero que la respuesta puede encontrarse en la atmósfera de cambios al interior de la Devotio Moderna. El hecho de que los salmos en el Libro de Horas fueran luego traducidos en su totalidad indica que hubo una intensificación de la vida espiritual en ciertas comunidades que pertenecían a la Devotio Moderna. Esta hipótesis se clarifica más al mirar en detalle los manuscritos que contienen el salterio en neerlandés medieval de la Devotio Moderna: estos no contienen la versión vernácula del Libro de Salmos, pero sí el salterio litúrgico, el cual fue usado en el Oficio Divino. El salterio de la Devotio Moderna fue compuesto de tal forma que los salmos pudiesen ser leídos de acuerdo a los esquemas litúrgicos (14). No fue concebido para el estudio, sino para la oración activa. En otras palabras, este libro fue destinado para aquellas personas que no entendían latín, pero que tenían suficiente tiempo para la oración. Aun cuando la Chronicon Windeshemense nos dice que Johannes Scutken tradujo el salterio para los hermanos legos de Windesheim, lo más probable es que el actual salterio de la Devotio Moderna haya sido pensado para mujeres devotas.

En primer lugar, podríamos pensar en las canonesas regulares de San Agustín (15). Algunas comunidades de las Hermanas de la Vida Común eligieron regirse por la Regla de San Agustín y luego, en el siglo quince, fueron fundados nuevos monasterios de canonesas. Para estas mujeres, rezar el Oficio Divino era ciertamente, después de todo, la razón más importante de sus existencias. Debido a que muchas de ellas no dominaban el latín, un salterio traducido podría ser muy útil. Si observamos detenidamente los salterios de la Devotio Moderna que han sobrevivido y que han sido identificados, menos del $10 \%$ estaba en manos de las canonesas. Por lo tanto, es poco probable que la traducción de este salterio haya sido destinada específicamente para ellas.

Tendremos que buscar otro tipo de comunidad de mujeres. Es importante comprender que la traducción del salterio litúrgico en latín en la parte norte de los Países Bajos fue un acontecimiento revolucionario. En las manos de los illiterati (los 'iletrados') -que en su significado medieval hace referencia a las personas que no entendían latín - se encontraba ahora un nuevo libro que hasta ese momento solo había podido ser leído y usado por gente instruida y religiosa. Esta es la razón por la cual deberíamos considerar la posibilidad de relacionar la transición que va desde el Libro de Horas de Geert Grote -un libro que tenía poca conexión con la liturgia oficial- hasta la traducción del salterio de la Devotio Moderna, con otro tipo de transición.

(14) DESPLENTER 2004b, p. 202-203.

(15) Para las canonesas regulares de San Agustín of Windesheim, ver SCHEEPSMA 2004. 
En el siglo quince, muchas comunidades de mujeres se transformaron en verdaderos monasterios al adoptar la regla de San Agustín en vez de la regla de la Orden Tercera Franciscana (o en vez de rechazar toda Regla) (16). Entonces, puede ser que el salterio en neerlandés medieval de la Devotio Moderna fuera usado por mujeres que planeaban adoptar la regla de San Agustín. De esta forma, ellas se comprometerían a orar el Oficio Divino, y para ellas una traducción del salterio litúrgico sería de mucha ayuda para una mejor y más rápida comprensión de este Officium Divinum. Hay sin embargo que descartar también esta hipótesis, puesto que solo una pequeña parte de los salterios pertenecía a las comunidades de mujeres que posteriormente adoptaron la regla de San Agustín.

Por lo tanto, está claro ahora que una nueva hipótesis se debería fundamentar en lo que sabemos acerca de las comunidades de mujeres en la parte norte de los Países Bajos que siguieron la Orden Tercera Franciscana (la así llamada Orden Terciaria) (17). Durante mi investigación aclaré el hecho que casi el $75 \%$ de los salterios de la Devotio Moderna fueron hechos para mujeres o usados en comunidades de mujeres que nunca adoptaron otra regla que la Orden Tercera Franciscana. Además, la mayoría de estos libros eran leídos en el noroeste de los Países Bajos, en la región actualmente conocida como el sur y el norte de Holanda y Utrecht. En otras palabras, lo más probable es que el salterio de la Devotio Moderna fuera primeramente introducido en la zona occidental del norte de Holanda. Esto es curioso, puesto que, como ya lo he mencionado, la mayoría de los estudiosos hasta ahora han propuesto que la tercera traducción del Salterio al neerlandés medieval fue realizada en Windesheim, en la región oriental del norte de los Países Bajos. Otro hecho notorio acerca de las copias del salterio de la Devotio Moderna es que son muy semejantes en apariencia. Este es un indicador importante de la posibilidad de que el salterio fuera introducido simultáneamente en varias comunidades en Holanda y Utrecht.

Esto no implica necesariamente, por otra parte, que Johannes Scutken no haya completado la traducción del Salterio de Geert Grote. Si esta traducción fue de hecho realizada en Windesheim, es casi seguro que este Salterio fue conocido por los Hermanos de la Vida Común en Deventer. Existieron conexiones muy cercanas entre estos Hermanos y Windesheim y, de hecho, los primeros habitantes de Windesheim vivieron primeramente en la casa de Deventer. Es por lo tanto interesante saber que en un breve período después de la fundación en 1387 de Windesheim, una gran cantidad de Hermanos de Deventer fue enviada al oeste del país para comenzar nuevas comunidades de Hermanos y Hermanas de la Vida Común. Entre ellos reconocemos a los instigadores de lo que se transformaría en la más grande organización religiosa en el norte de los Países Bajos, el Capítulo de Utrecht. Esta organización fue oficialmente fundada en el año 1401 y se unió a los Hermanos y Hermanas de la

(16) Una descripción de esta evolución en el noroeste de Alemania se encuentra en G. Rehm, Die Schwestern vom gemeinsamen Leben im nordwestlichen Deutschland. Untersuchungen zur Geschichte der Devotio moderna und des weiblichen Religiosentums, Berlin 1985 (Berliner Historische Studien, Bd. 11, Ordensstudien V). Una evoución bastante similar puede observarse en los Países Bajos, especialmente en el norte. (ver YPMA 1949, p. 10-17).

(17) Muchos nuevos datos y números sobre los terciarios en la Diócesis de Utrecht pueden encontrarse en GOUDRIAAN 1998. 
Vida Común en la diócesis de Utrecht que había adoptado la regla de la Orden Tercera Franciscana. Más del 60\% de las comunidades, que eran miembros de este Capítulo de Utrecht, habían tenido contacto con Geert Grote o la casa de Hermanos de Deventer (18). Es bastante probable que alguno de los 'pioneros' dentro de ese Capítulo completase el Salterio y no el bibliotecario de Windesheim.

Como corolario, el Salterio fue ampliamente usado y, lógicamente, fue casi seguramente destinado para el uso de los miembros de la Orden Tercera, quienes vivían en el noroeste de los Países Bajos. Existe, sin embargo, un problema: la traducción del Salterio Litúrgico implica que el usuario de este poseía un buen conocimiento de la liturgia en general y del Oficio Divino más específicamente. Este no era, hasta donde sabemos, el caso de los miembros de la Orden Tercera. Para ellos, un Salterio Litúrgico traducido solo podría haber servido para la devoción personal. Un análisis de la forma en que algunos textos en el Salterio fueron traducidos confirma esta hipótesis (19). Estos libros no tenían uso durante el Oficio Divino (por ejemplo, como un recurso para un mejor entendimiento de los textos litúrgicos). Uno podría haber usado estos textos aún de mejor manera por cuenta propia, sin el texto en latín. Entonces, podríamos preguntarnos, ¿por qué un Salterio Litúrgico tuvo que ser traducido y no el Libro de Salmos tradicional que aparece en la Biblia? No hemos encontrado documentos en los cuales se establece la verdadera razón de esto; por lo tanto trataremos de averiguar quién pudo haber tomado la iniciativa de traducir un Salterio Litúrgico.

Por lo que sabemos acerca del conocimiento del latín en las comunidades de mujeres de la Edad Media, podemos estar casi seguros que el Salterio Litúrgico no fue completado por los terciarios franciscanos. El libro debió haber sido introducido en sus comunidades por otras personas, y la uniformidad textual de todos estos Libros de Salmos indicaría que esta introducción se produjo en una forma más o menos organizada, por ejemplo, por iniciativa de los pastores o de los líderes espirituales del Capítulo de Utrecht. De los manuscritos que todavía están disponibles podemos concluir que la distribución de la traducción del Salterio en las comunidades de la Orden Tercera en Holanda debió haber ocurrido entre 1415 y 1420 (20). Esta conclusión, hecha sobre la base de una investigación de los códices, hace muy tentadora la hipótesis de que la distribución estuvo conectada con las ambiciones del Capítulo de Utrecht (21). En 1418 algunos miembros de este Capítulo le solicitaron al obispo de Utrecht la posibilidad de adoptar la regla de San Agustín para así convertirse en verdaderos monasterios. El obispo aprobó esta petición y concedió al mismo tiempo el permiso para fundar un nuevo Capítulo, conocido más tarde como el Capítulo de Sion (22). Los primeros dos miembros de este Capítulo fueron dos conventos en Holanda donde estaban a cargo Hermanos que habían pertenecido a la casa de Deventer anteriormente. De hecho, ha sido sugerido que la petición fue hecha por estos dos hombres y no por todos los

(18) GOUDRIAAN 1998, p. 231.

(19) DESPLENTER 2004b, p. 204-210.

(20) ID., p. 211.

(21) Sobre la evolución del Capítulo de Utrecht, YPMA 1949, p. xiv, KoORN 1996 y GoudriaAn 1998.

(22) Sobre el Capítulo de Sion, ver YPMA 1949. 
conventos del Capítulo de Utrecht (23). Debido a que solo pocos conventos realmente adoptaron la regla de San Agustín, esta suposición podría ser correcta. En aquellos tiempos de evolución dentro del Capítulo de Utrecht, un Salterio Litúrgico traducido podría haber sido introducido en alguno de los cincuenta conventos que eran miembros de del Capítulo, con el objeto de familiarizar a las mujeres con el Oficio Divino. Como ya he mencionado, la mayoría de los miembros de la Orden Tercera no sabía suficiente latín como para entender los textos en aquellos servicios. Quizás los líderes espirituales consideraron que los conventos estarían más ansiosos por adoptar la regla de San Agustín si estos sabían en qué consistía el Oficio Divino: los textos de la Devotio Moderna fueron vistos realmente como un medio para cambiar la conducta del lector (24). Si esta fue realmente la filosofía detrás de la introducción del Salterio Litúrgico, tuvo muy poco éxito: solo unos pocos conventos adoptaron efectivamente la regla de San Agustín.

La razón por la cual esto ocurrió se debe posiblemente a que la supuesta introducción no fue una decisión del mismo Capítulo de Utrecht. Aunque los decretos del Capítulo que datan desde antes del año 1427 están perdidos, la introducción del Salterio Litúrgico entraría en conflicto con decretos posteriores (25). Por ejemplo, en el año 1437 el Capítulo prescribió que fratres et sorores non facient breviaria teutonicalia scribi (26). De hecho, la mayoría de los así llamados breviarios para laicos -libros que mencionaré en breve- también contenían un Salterio litúrgico. Sin embargo, encontré muchos breviarios para laicos escritos después del año 1437 y que fueron usados en los conventos del Capítulo de Utrecht. Quizás deberíamos considerar este decreto como parte de una nueva evolución dentro del Capítulo después del año 1430. Como ya mencioné, desde el año 1418 hasta el año 1430, los miembros del Capítulo parecen haber sido estimulados a adoptar la regla de San Agustín. Para transformarse en un verdadero monasterio, los habitantes tenían que saber latín para rezar el Oficio Divino. Probablemente debido a que muchos de estos nuevos monasterios tenían problemas para llegar a formar parte de un Capítulo Agustino ya existente (27), el Capítulo de la orden Tercera esperaba desalentar futuras evoluciones en sus conventos. En el año 1441, por ejemplo, el Capítulo de Utrecht prohibió a las mujeres que pertenecían a este el aprender latín. Ellas, al mismo tiempo, nunca más podrían cantar en iglesias parroquiales (28). Podemos considerar esto como un acto de autopreservación del Capítulo de Utrecht. Solo al prohibir a las mujeres el aprendizaje del latín y el canto en las iglesias se lograría prevenir que los conventos se transformaran en

(23) YPMA 1949, p. 34.

(24) N. Staubach, 'Pragmatische Schriftlichkeit im Bereich der Devotio moderna', in: Frühmittelalterliche Studien 25 (1991), p. 418-461, p. 425.

(25) Una edición de los decretos del Capítulo de Utrecht está en DE KoK 1927.

(26) Cf. DE KoK 1927, p. 120-121

(27) Los Capítulos Agustinos ya existentes, como por ejemplo, el Capítulo de Windesheim, empezaron a mostrarse muy reacios, a lo largo del siglo XV, a incorporar nuevos monasterios femeninos. Es posible que la razón principal haya sido el temor a la pesada carga que implicaba la administración material de estas casas (cf. KOORN 1996, p. 141 y SCHEEPSMA 2004, p. 11).

(28) Item de cetero non discent sorores cantum nec cantabunt in ecclesiis parochi nec legent latinum nec loquentur (DE KOK 1927, p. 123). 
monasterios. Posiblemente el Capítulo de la Orden Tercera se sintió suficientemente fortalecido como para sobrevivir en forma autónoma, sin tener que servir como 'cuidador' de los monasterios Agustinos.

Algunos de los Libros de Salmos litúrgicos traducidos están acompañados por versiones de los oficios litúrgicos en neerlandés medieval. En su versión original en latín, estos textos eran parte del Breviario. Antes de mi investigación, los académicos solo estudiaban estos libros, denominados 'Breviarios Laicos', por sus decoraciones. En mi tesis doctoral he hecho un análisis completo de estos libros, y el resultado más interesante fue el descubrimiento de lo que he llamado el 'Breviario Laico Básico' (29). He encontrado que un pequeño conjunto compuesto de veinticinco oficios litúrgicos traducidos, los más importantes del año, fueron introducidos junto al Salterio litúrgico en algunos conventos de la Orden Tercera. Debido a que uno de esos oficios está compuesto en honor a San Francisco, podemos estar casi seguros que existe un vínculo entre el 'Breviario Laico Básico' y el Capítulo de la Orden Tercera de Utrecht. Por lo demás, he encontrado la versión en neerlandés medieval del oficio Franciscano copiada principalmente en manuscritos que fueron redactados o usados en conventos que eran miembros del Capítulo. Sin embargo en la mayoría de los casos, la traducción del Libros de Salmos litúrgicos era distribuida independientemente, sin la versión en neerlandés medieval de los oficios litúrgicos. Aparentemente solo en Delft y Utrecht el 'Breviario Laico Básico' fue introducido en los conventos de la Orden Tercera, e incluso le fueron allí añadidos otros oficios traducidos. Teniendo en cuenta a su público lector, podemos asumir que el 'Breviario Laico Básico' tuvo la misma función que el Salterio traducido: en primera instancia fue usado para la devoción personal.

Como lo he mencionado, Delft era en ese tiempo una importante ciudad en el sur de Holanda, y parece haber sido un centro muy importante en la producción y distribución del Breviario laico y, por lo tanto, del Salterio de la Devotio Moderna. En lo que sigue, concentraremos por lo tanto nuestro estudio en el caso de Delft.

Alrededor de una cuarta parte de las traducciones del Salterio litúrgico y de los breviarios fue realizada en Delft. Esos manuscritos poseen una decoración muy característica que facilita su reconocimiento (30). Fue en estos libros de Delft donde pude descubrir que no solo la decoración, sino que también algunos textos presentes en los breviarios eran propios de la ciudad (31). Después de lograr conectar algunas traducciones con Delft, era tiempo de averiguar más acerca de la historia religiosa de esa ciudad. Anteriormente he mencionado que la adopción de la regla de San Agustín en el Capítulo de la Orden Tercera de Utrecht recayó en la iniciativa de unos pocos hombres, de Hermanos que habían anteriormente pertenecido a la casa de Deventer. Uno de ellos, Pieter Gerritszoon, dirigía una nueva casa en Delft y se había transformado en el líder espiritual de algunos de los cinco conventos terciarios

(29) DESPLENTER 2004b, p. 229-253.

(30) Para la ornamenteción característica de los manuscritos de Delft, ver Die goldene Zeit der holländischen Buchmalerei, Stuttgart/Zürich 1990 (Catalogue of the Exhibitions in Utrecht, Rijksmuseum Het Catharijneconvent 12/10/1989-02/11/1990 and New York, The Pierpont Morgan Library 3/1/1990-5/6/1990), p. 185-197, 265-284.

(31) DESPLENTER 2004a, p. 140-142. 
en esta ciudad (32). Se puede asegurar con mucha razón que Gerritszoon, si es que no fue el responsable, estuvo en todo caso muy complacido con la decisión de uno de aquellos conventos, el de St.-Agnes, de adoptar la regla de San Agustín en 1423 (33). Este se transformó en parte del nuevo Capítulo Agustino de Sion, la unión a la cual el propio convento de Gerritszoon pertenecía, y que de hecho fue uno de sus primeros miembros. Está claro además que Gerritszoon quedó muy enfadado al enterarse que otro convento de la Orden Tercera de Delft, el de St-Barbara, no adoptaría la regla de San Agustín. Él renunció incluso a su 'trabajo' como confesor en ese lugar debido a este hecho (34).

Aun cuando he encontrado Libros de Salmos litúrgicos y breviarios laicos en neerlandés medieval que fueron usados, o destinados para serlo, en diferentes conventos de la Orden Tercera en Delft, solo en St.-Agnes sabemos con seguridad que tales libros fueron escritos en el mismo convento. Debido a que la decoración de estos y otros manuscritos que fueron hechos en Delft es muy similar, algunos académicos han concluido que todos estos libros fueron escritos en St.-Agnes (35). Esta interpretación no puede ser válida: demasiados manuscritos (más de noventa, de hecho) con este tipo de decoración son conocidos, y nadie puede siquiera estimar cuantos libros fueron destruidos durante los siglos pasados. Sin embargo, no está claro el lugar exacto donde estos libros fueron escritos. Podríamos considerar la posibilidad que hubiera más de un convento o incluso un taller en la ciudad en donde estos manuscritos fueron copiados. Si este hubiera sido el caso, debió haber existido una muy cercana cooperación entre estas distintas instancias. De todas maneras, parece ser que al menos una parte de la decoración fue realizada por las mismas mujeres. De hecho, en un manuscrito de St.-Agnes [Ms. Brussel, KB, 21696] pudimos encontrar la nota 'scriptus et illuminatus' [fol. 117r]. En otras palabras, podemos estar seguros que no todos los libros escritos fueron llevados a otro lugar, por ejemplo a un taller, para ser iluminados.

De mucho interés para la relación entre texto e imagen en los breviarios laicos y en los salterios de Delft, es el artículo escrito hace unos quince años por el historiador del Arte James Marrow, titulado Text and Image in two fifteenth-century Dutch Psalters from Delft (36). En uno de los libros de salmos que Marrow describe [ms. Cambridge, Mass., Harvard University, Houghton Library, Ms. Typ. 132] se da una característica que es bastante particular y que tendrá que ser estudiada en la perspectiva más completa de la tradición de los salterios en neerlandés medieval. En ese manuscrito hay un ciclo de ilustraciones al margen del texto, y que llaman la atención hacia los aspectos históricos de muchos de los Salmos y Cánticos. Se

(32) Sobre Pieter Gerritszoon, ver B.A. Vermaseren, Het klooster "Sancta Maria in Monte Sion" tussen Delft en Rijswijk 1433-1574. Een vrucht van de Moderne Devotie, Pijnacker 1981, p. 25-33.

(33) Nuevos datos concernientes al convento de St.-Agnes se encuentran en GoudRIAAN 1998, p. 242 en 246.

(34) Sobre la historia de Santa Bárbara, ver G. Verhoeven, 'De kronieken van twee Delftse tertiarissenconventen', in: Ons Geestelijk Erf 74 (2000), p. 105-152.

(35) Así lo hizo por ejemplo el famoso historiador del Arte holandés Byvanck in his 'Noord-Nederlandsche miniaturen. V: Een schilderschool te Delft', in: Oudheidkundig Jaarboek, $3^{\text {de }}$ serie 3 (1923), p. 188-201.

(36) In Spiritualia Neerlandica. Opstellen voor dr. Albert Ampe, Antwerpen 1990, p. 341-352 [also in OGE 64 (1990), p. 41-52]. 
encuentra, por ejemplo, un retrato de Esdras [(fol. 46r)], con un típico rollo de Delft que contiene la inscripción: Esdras die scriver [Esdras el escritor]. Ciertamente, estas ilustraciones marginales hacen referencia a los así llamados tituli, pequeñas introducciones a algunos de los Salmos, las cuales normalmente aparecen al inicio de estos. Esdras die scriver, por ejemplo, se refiere al título anterior al Salmo 1. En neerlandés medieval el título es Also als die meesters segghen so screef esdras desen psalm [Como los maestros dicen, Esdras escribió este Salmo]. Sin embargo, en este manuscrito, los tituli son sacados de su posición habitual previa al Salmo y son puestos juntos en otro lugar del libro.

La conclusión de Marrow acerca de la función de estas ilustraciones marginales y de las ilustraciones en las páginas opuestas a los títulos es interesante: él consideró que estas tenían otra función a la usual en los manuscritos medievales (37). Comúnmente, las imágenes ilustraban la narración copiada en el manuscrito. Sin embargo, de acuerdo con Marrow, en este Salterio la función de estas ilustraciones al margen era la de entregar más detalles acerca del significado de los textos que estas acompañan. Es posible, sin embargo que el enfoque que plantea Marrow con respecto a los usuarios del Libro de Salmos sea incorrecto, y por consiguiente su interpretación de la función de las ilustraciones. Uno de los dos Libros de Salmos que él analiza y discute en su artículo, el ms. London, BL, Egerton 1152, fue destinado al convento de la Orden Tercera de St.-Ursula en Delft (38). Esta casa nunca adoptó la regla de San Agustín, y por lo tanto -como ya expliqué al comienzo de este estudio- es muy poco probable que las religiosas de ese convento hayan rezado el Divinum Officium. Sin embargo, Marrow sugiere que las ilustraciones tuvieron su función particular y inusual debido a que los lectores todavía leían el Divinum Officium (en latín). De hecho él olvidó que los textos en los Libros de Salmos estudiados por él fueron escritos en vernáculo y que estos libros tuvieron una función totalmente diferente a la de los textos en latín. Si bien el artículo de Marrow es relativamente breve, contiene no obstante conclusiones que tendrán que ser comprobadas al compararlas con otros Libros de Salmos. Por consiguiente, en mi nuevo proyecto de investigación [cf. n. 13], será necesario incluir el estudio de las ilustraciones en los Libros de Salmos traducidos y su impacto en los usuarios de esos libros.

Como conclusión, es necesario revisar el marco general en el cual se encuentran el Libro de Salmos litúrgico y el Breviario laico en neerlandés medieval. No debemos olvidar que aún no hemos respondido a la pregunta que se formula en el título de este estudio: ¿fueron estos libros escritos por hombres para dominar la devoción femenina? La respuesta es 'sí' y 'no'. Hace más de 35 años, el profesor Post publicó un libro que continúa siendo una obra de referencia para el estudio de la Devotio Moderna (39). Esto es lo que él escribió acerca de las mujeres en este movimiento religioso:

(37) MARRow 1990, p. 347-348 [47-48].

(38) Se sabe poco acerca del convento del orden terciario de St.-Ursula en Delft. La mayor parte de los datos y referencias a una literatura anterior se encuentran en GOUDRIAAN 1998, p. 242.

(39) Post 1968 
Las hermanas eran los miembros pasivos de la Devotio Moderna, en cuanto ellas no predicaban o ejercían influencia religiosa alguna sobre una cierta categoría de personas al exterior a la comunidad, a no ser a través del ejemplo. Ellas no escribieron ningún tratado religioso, a diferencia de algunos de los Hermanos, pero pusieron en práctica las enseñanzas que habían recibido de parte de Geert Grote y sus discípulos (40).

¿Es esta realmente una apreciación adecuada? Si consideramos el Libro de Salmos y el Breviario laico en neerlandés medieval, tendríamos que responder afirmativamente. Ya he aclarado que estos libros fueron probablemente introducidos en algunos de los conventos de la orden terciaria para persuadir a las mujeres para que adoptaran la regla de San Agustín. Muy probablemente, los líderes espirituales del Capítulo de Utrecht, todos ellos sacerdotes, fueron los autores de este plan. Esta introducción masiva corresponde perfectamente con los objetivos de la reforma que caracteriza a la Devotio Moderna desde la mitad del siglo quince en adelante (41). Al interior de este movimiento, la espiritualidad individual y devoción personal tuvieron que ser practicadas para la regularización de la vida espiritual. De todos modos, la introducción del Libro de Salmos y el breviario en neerlandés medieval parece haber sido impulsada por el jefes espirituales del movimiento. Podemos deducir esto de la gran cantidad de copias de estos libros que fueron hechas en tan corto periodo de tiempo. La naturaleza de los textos -traducciones de himnos bíblicos y litúrgicos- apunta a que los patrocinadores de esta iniciativa pertenecieron al círculo de los literati, y seguramente fueron hombres religiosos. Esto no quiere decir que las comunidades de mujeres meramente hicieran lo que se esperaba de ellas: de hecho, muchos conventos rechazaron adoptar la orden de San Agustín.

Un efecto colateral de la introducción de los libros litúrgicos traducidos fue que la estructura de la vida cotidiana de los terciarios podría ser controlada. Si estas mujeres leyeron los oficios traducidos como debieron -muchos de los Libros de Salmos y Breviarios contenían instrucciones de uso- entonces prácticamente no les quedó tiempo para leer o incluso escribir 'peligrosos' textos místicos. Otros académicos ya han dado cuenta del hecho que la Orden Tercera en Holanda o Utrecht produjo muy pocos escritos místicos (42). Debido a que los miembros de esta Orden, especialmente en sus primeros años de existencia, tuvieron que dedicar bastante tiempo a la edificación de sus comunidades, un Libro de Salmos traducido debió haber sido más que suficiente para satisfacer la necesidad de textos religiosos. De este modo, la introducción de versiones en neerlandés medieval de los textos litúrgicos en los conventos terciarios en el primer cuarto del siglo quince significó una gran dosis de pasividad de parte de las mujeres. Estos libros fueron simplemente recibidos, copiados y leídos. De hecho, algunas de las primeras copias del libro de salmos y del breviario traducidos que estudié ni siquiera habían sido escritas por mujeres. Por otra parte, durante el transcurso del siglo quince empezaron a aparecer

(40) Post 1968, p. 497.

(41) Sobre esta reforma, ver MERTENS 1995, p. 129-130.

(42) Ver por ejemplo F.W.J. Koorn, 'Hollandse nuchterheid ? De houding van de Moderne Devoten tegenover vrouwenmystiek en -ascese', in: OGE 66 (1992), p. 113-114. 
muchas subtradiciones de oficios traducidos del breviario, tradiciones que eran en muchos casos muy locales. Esto está, sin lugar a dudas, conectado con la evolución dentro de la Devotio Moderna, la así llamada "distancia del mundo" (43), y que hizo que casi todos los conventos de mujeres tuvieran su propio desarrollo. Es posible que los oficios litúrgicos que fueron traducidos después que el 'Breviario laico Básico' fuese introducido hayan sido realizados por los miembros de la Orden Tercera. Después de todo, un convento necesitaba de solo una mujer que dominara el latín para traducir sus propios oficios. Además, en el transcurso del siglo quince, algunos de los conventos de la Orden, por ejemplo en Delft, se habían enriquecido mucho. Esto significó que atraían más mujeres de la clase alta, mujeres que en algunos casos leían y escribían en latín.

Sin embargo, no he encontrado prueba alguna de que una mujer haya traducido textos litúrgicos en latín. Yo considero que el 'caso de Delft' es característico de la situación en los conventos de mujeres en Holanda y Utrecht: solo conocemos uno de los conventos donde los manuscritos fueron en realidad escritos e iluminados, el de St.-Agnes. Podría no ser una coincidencia que St.-Agnes adoptara la regla de San Agustín en un período temprano y que así, muy probablemente, sus religiosas tuvieran un nivel intelectual superior al que se podía encontrar en otros conventos en Delft. Es sin embargo una lástima que sepamos tan poco acerca del convento de St.Ursula en Delft. Muchos manuscritos que fueron hechos en Delft aparentemente fueron destinados para el uso en aquellas comunidades de la Orden Tercera.

Los tipos de textos y manuscritos que he estado estudiando no nos facilitan la posibilidad de debilitar el axioma del profesor Post que sostiene que las mujeres dentro de la Devotio Moderna eran pasivas. Ellas dependían en una extensa medida de lo que sus líderes espirituales masculinos les proveían para su adoctrinamiento espiritual. De todas maneras me gustaría finalizar esta exposición de una forma positiva: desde el último cuarto del siglo quince en adelante, las mujeres de las comunidades de la Devotio Moderna produjeron sus propios textos (44). Es cierto, por ejemplo, que ellas escribieron vitae de sus Hermanas, además de colecciones de canciones y sermones e incluso oraciones en lengua vernácula. Supongo que no es coincidencia que al mismo tiempo la producción de libros de salmos y breviarios traducidos comenzó a decaer. Desde Delft y hacia el norte de Holanda, por ejemplo, no he encontrado breviarios en neerlandés medieval que hubiese sido escritos después del año 1500 (45). Es bastante probable que para ese tiempo las mujeres vivenciaran su propia espiritualidad también de una forma diferente, y con sus propios textos.

(43) Descrito en op.cit., MERTENS 1995, p. 140 and KOORN 1996, p. 140.

(44) MERTENS 1995, p. 130.

(45) En 1480 se realizó en Delft la primera edición impresa del Salterio de la Devotio Moderna escrito en neerlandés medeival. (Die Duytsche Souter; cf. G. van Thienen, J. Goldfinch, Incunabula printed in the Low Countries. A census, Nieuwkoop 1999 (Bibliotheca Bibliographica Neerlandica 36), nr. 1838). Fue impreso por última vez en Leiden, en 1510 (cf. W. Nijhoff, M.E. Kronenberg, Nederlandsche Bibliographie van 1500-1540, 's-Gravenhage 1923-1971, nr. 363). Por otra parte, no exisitió una edición impresa de un 'breviario laico' en neerlandés medieval. 


\section{RESUMEN}

Muchos manuscritos del siglo XV contienen una versión vernácula del salterio litúrgico y de algunos oficios litúrgicos. Esta traducción se hizo dentro del movimiento religioso influyente del Devotio Moderna del período del medioevo tardío, y distribuida principalmente en los conventos del tercer orden de San Francisco en Holanda. Debe haber sido alrededor del año 1418 que tomó lugar esta distribución, y lo más probable era con la intención de familiarizar a las tercianas con del Divinum Officium. En las comunidades del tercer orden franciscano, el Oficio Divino en latín no era generalmente recitado. A la altura del año 1418, algunos de los líderes espirituales masculinos de esos conventos querían que se volviesen comunidades de claustro, donde la regla de San Agustino se seguiría. Desde aquel momento, el orar el Oficio Divino llegó a ser obligatorio. Entonces, debían haber compuesto y distribuido una síntesis del Oficio Divino en la forma de un breviario vernáculo laical.

\section{ABSTRACT}

Quite a few Middle Dutch manuscripts from the $15^{\text {th }}$ century contain a vernacular version of the liturgical psalter and of some liturgical offices. This translation was made within the influential late medieval religious movement of the Devotio Moderna and was primarily distributed in convents of the third order of St. Francis in Holland. It must have been around 1418 that this distribution took place, most probably to make the female tertiaries familiar with the Divinum Officium. In communities of the Franciscan third order, the Latin Divine Office was not usually recited. By 1418 , some of the male spiritual leaders of those convents wanted to have them evolve into cloisters where the rule of St. Augustine would be followed. From that moment on, the praying of the Divine Office became obligatory. Therefore, they must have compiled and distributed a summary of the Divine Office in the form of a vernacular lay breviary.

\section{BIBLIOGRAFÍA}

De Kok 1927: De Kok 1927: D. de Kok, Bijdragen tot de Geschiedenis der Nederlandsche Klarissen en Tertiarissen vóór de Hervorming, Utrecht 1927 (Werken uitgegeven door het Historisch Genootschap, derde serie nr. 52).

Desplenter 2004a: Y. Desplenter, 'Songs of Praise for the 'Illiterate'. Latin Hymns in Middle Dutch Prose Translation', in: Th. de Hemptinne, M. E. Góngora (eds.), The Voice of Silence: Women's Literacy in a Men's Church, Turnhout 2004, p. 127-142 (Medieval Church Studies 9).

Desplenter 2004b: Y. Desplenter, Liturgische lofzangen in het Middelnederlands. Een onderzoek naar de aard, verspreiding en functie van Middelnederlandse vertalingen van Latijnse hymnen en sequensen, Diss. Universiteit Gent, 2004 [inédito].

Goudriaan 1998: K. Goudriaan, 'De Derde Orde van Sint-Franciscus in het bisdom Utrecht. Een voorstudie', Jaarboek voor Middeleeuwse Geschiedenis 1 (1998), p. 205-260.

Koorn 1996: F.W.J. Koorn, 'Het Kapittel van Utrecht', in: Windesheim 1395-1995. Kloosters, teksten, invloeden. Voordrachten gehouden tijdens het internationale congres '600 jaar Kapittel van Windesheim'. 27 mei 1995 te Zwolle, Nijmegen 1996 (Middeleeuwse Studies 12), p. 131-142.

Th. Mertens e.a., Boeken voor de eeuwigheid. Middelnederlands geestelijk proza, Amsterdam 1993 (Nederlandse literatuur en cultuur in de middeleeuwen 8). 
Th. Mertens, 'Mystieke cultuur en literatuur in de Late Middeleeuwen', in: Grote lijnen. Syntheses over Middelnederlandse letterkunde, Amsterdam 1995, p. 117-135 en 205217 (Nederlandse literatuur en cultuur in de middeleeuwen 11).

Post 1968: R. R. Post, The Modern Devotion. Confrontation with Reformation and Humanism, Leiden 1968 (Studies in Medieval and Reformation Thought III).

Scheepsma 2004 ç: W. Scheepsma, Medieval Religious Women in The Low Countries. The 'modern devotion', the Canonesses of Windesheim, and their writings, Woodbridge 2004.

Ypma 1949: E. Ypma, Het generaal kapittel van Sion. Zijn oorsprong, ontwikkeling en inrichting, Nijmegen/Utrecht 1949. 